\title{
Diversitas dalam Dunia Kerja: Peluang dan Tantangan bagi Disabilitas
}

\section{Diversity in Work Realm: Opportunity and Threat to Disability}

\author{
Abdul Latief Danu Aji ${ }^{1}$, Tiyas Nur Haryani ${ }^{2}$ \\ ${ }^{1}$ Fakultas Psikologi Universitas Muhammadiyah Surakakarta \\ ${ }^{2}$ Program Studi Ilmu Administrasi Negara Fakultas Ilmu Sosial dan Politik Universitas \\ Sebelas Maret \\ abdullatiefdanuaji@gmail.com, tiyasnurharyani@staff.uns.ac.id
}

\begin{abstract}
Abstrak
Diversitas dalam angkatan kerja di era globalisasi saat ini telah mendapatkan perhatian yang lebih. Adanya ratifikasi terhadap konvensi ekosob dan konvensi Hak Asasi Manusia (HAM) menjadi peluang munculnya diversitas dalam angkatan kerja. Indonesia telah meratifikasi konvensi hak-hak disabilitas dan di Kota Surakarta sebdiri telah memiliki Perda No 4 Tahun 2008 Tentang Kesetaraan Kaum Difabel. Artikel ini mendiskusikan mengenai keanekaragaman dalam angkatan kerja yang pada dasarnya memberikan peluang bagi mereka yang memiliki perbedaan fisik dan mental. Namun, dalam sebuah peluang keanekaragaman yang ada tersebut muncul pula tantangan bagi kaum disabilitas dalam memasuki dunia kerja. Tujuan penulisan artikel ini adalah untuk mendiskusikan peluang-peluang bagi kaum dasabilitas dalam memasuki dunia kerja yang telah tertuang dalam berbagai peraturan perUndang-Undanagn baik di tingkat nasional dan daerah sekaligus mendeskripsikan tantangan yang mereka hadapi. Metode yang digunakan dalam penulisan artikel ini dengan melakukan kajian pustaka berbagai buku teks, jurnal baik internasional dan nasional serta analisis konten dari peraturan perUndang-Undangan yang menyangkut tentang ketenagakerjaan dan disabilitas. Data dalam artikel ini dikumpulkan melalui studi pustaka dan observasi. Dasar analisis yang digunakan adalah analisis konten dari regulasi ketenagakerjaan dan hak disabilitas yang telah diberlakukan di Indonesia pada umumnya dan Kota Surakarta pada khususnya. Temuan yang ada menyebutkan bahwa peraturan perUndang-Undangan yang ada telah memberikan peluang kesetaraan bagi kaum disabilitas memasuki dunia kerja, akan tetapi tantangan sosial masih menjadi penghambat kesetaraan disabilitas dalam kesempatan kerja. Implikasinya penyedia lapangan kerja harus memenuhi hak kaum disabilitas dalam kuota kerja yang telah diatur dalam perUndang-Undangan.
\end{abstract}

Kata kunci: disabilitas, diversitas, kesempatan kerja, manajemen sumber daya manusia

\begin{abstract}
Diversity in workforce in globalization era has gotten more attention. The ratification of economic, socio-cultural convention and human right convention give the opportunity to
\end{abstract}


diversity to appear in workforce. Indonesia has ratified the convention of disability rights and in Surakarta City, there has been Perda (Local Regulation) No.4 of 2008 about Equality of Difable (those with different abilities). This article discussed diversity in workforce basically giving opportunity to those having different physique and mentality. However, in an opportunity of diversity existing, challenge also appears to the disabled in entering into world realm. This research aimed to discuss the opportunities for the disabled to enter into work realm as included in some legislation at both national and local levels and to describe the challenge they encounter. The methods employed were library research on textbook, international and national journal, and content analysis on legislation pertaining to manpower and disability. The data of research was collected using library study and observation. The analysis was carried out using content analysis on manpower regulation and disability right that have been enacted in Indonesia in general and Surakarta City in particularly. The finding of research showed that the existing legislation had given the disabled the equal opportunity of entering into work realm, but social challenge still inhibited the equality of disability in getting job opportunity. The implication was that job opportunity provider should fulfill the right of the disabled in job quota as governed in the legislations.

\section{Keywords: disability, diversity, job opportunity, human resource management}

\section{A. Latar Belakang}

Era globalisasi sekarang ini, memang dituntut hasil-hasil kerja yang serba cepat. Setiap instansi dituntut oleh customer atau citizen cepat dalam melayani dan memperluas pangsa pasarnya. Perusahan dan instansi penyedia lapangan kerja menginginkan kinerja yang optimal dari para tenaga kerjanya. Sayangnya tidak semua sumber daya manusia memiliki kapasitas yang sama. Keanekaragam khususnya terkait kondisi fisik seseorang menjadi pertimbangan pemilik dunia usaha dan/atau penyedia lapangan kerja dalam memilih tenaga kerja yang mereka gunakan. Keanekaragaman yang ada pada dasarnya tidak boleh ada pembedaan perlakuan atas manusia satu dengan yang lainnya baik itu dengan alasan suku, ras, agama atau golongan., demikian juga kondisi fisik atau dikenal dengan disabilitas (different ability/kemampuan berbeda). Perlakuan yang diskrimantif terhadap kaum disabilitas masih mudah kita jumpai dalam kehidupan sehari-hari kita. Pembangunan fisik insfrastruktur kota masih banyak yang belum responsif bagi kaum disabilitas, masih bnyak ditemukan kebijakan pemerintah yang belum memberikan ruang-ruang partisipasi publik bagi kaum disabilitas tersebut. Pihak swasta juga belum beritikad baik dalam membuka peluang yang sama atas mereka dalam pendidikan, ekonomi, budaya, politik dan sektor lainnya.

Kota Surakarta merupakan salah satu kota yang mendeklarasikan sebagai kota ramah disabilitas. Salah satu implementasinya adalah memberi ruang pada proses perencanaan. Selain itu, Kota Surakarta menjadi pusat rehabilitas disabilitas. 
Sayangnya aksesbilitas kaum disabilitas dalam menikmati kesetaraan masih jauh dari harapan. Meninjau konten regulasi yang telah memberikan peluang bagi disabilitas untuk bekerja dapat menjadi alternatif untuk memperkuat harga tawar disabilitas dalam dunia kerja. Keberadaan disabilitas memasuki dunia kerja adalah paksaan dan tidak semata karena aksi kemanusiaan. Namun, perlu pula dikaji tantangan yang dihadapi kaum disabilitas karena belum semua dunia kerja mampu mengimplementasikan anamat perUndangan-Undangan terkait masalah yang satu ini. Artikel ini akan medeskripsikan peluang dan tantangan kaum disabilitas dalam memasuki dunia kerja.

\section{B. Landasan Teori}

Banyak akademisi dan praktisi yang mengemukakan definisi diversitas, tetapi tidak ada yang diterima secara umum. Ada yang mengelompokkan diversitas kedalam dua karakteristik yaitu: karakteristik fisik dan karakteristik budaya. Guy dan Newman (dalam Condrey, Stephen E., 2005: 143) mendefinisikan diversitas merupakan "everyone is part of a group, either by gender, race, religion, ethnicity, age, physical ability, sexual orientation, skills, professional identification or tenure in an organization". Faktor diversitas disini adalah ras, budaya, ethnis, jender, usia, cacat (disability), dan pengalaman kerja. Untuk menyempurnakan disain perubahan kultural yang menghargai diversitas termasuk memodifikasi praktikpraktik dan prosedur-prosedur yang telah ada, berawal dari fungsi sumber daya manusia.

Junaedi, C. Marliana (2003: 22) menyimpulakn diversitas dari berbagai ahli dalam dua hal penting yaitu keanekaragaman atau perbedaaan yang dimiliki karyawan. Isu disabilitas dalam dunia kerja akan menjadi bagian dalam diversitas. Diungkapakan oleh Guy dan Newman (2005: 151) bahwa disabilitas adalah fakta lain dalam diversitas " along with gender, race, and age, disability is another facet of diversity".

\section{Pembahasan}

Dunia kerja di era globalisasi sekarang ini memang menuntut sumber daya manusia yang berkualitas. Tingkat persaingan yang ketat dalam mencari pekerjaan disebabkan oleh beberapa faktor diantar anadalah banyaknya pencari kerja baik di tingkat pendidikan dasar hingga perguruan tinggi, tidak seimbangnya kualifikasi jenis pekerjaan yang dibuka dengan jumlah tenaga kerja sesuai dengan kompetensi yang dibutuhkan dan sempitnya jumlah lapangan kerja di Indonesia.

Problem ketenagakerjaan di Indonesia saat ini adalah tingginya tingkat pengangguran, Pencari kerja yang memenuhi standar kesehatan fisik masih mengalami kesulitan dalam mencari pekerjaan, Bagi pencari kerja dari kaum rentan yaitu disabilitas juga masih mengalami problem yang lebih serius dalam mengakses kesempatan kerja. 


\section{a. Peluang bagi Disabilitas dalam Kesempatan Kerja}

Peluang yang dapat diisi oleh kaum disabilitas dalam dunia kerja sebetulnya telah diamanatkan dalam perUndangUndangan kita. Perundang-Undangan di tingkat nasional hingga daerah di Kota Surakarta telah memberikan ruang bagi disabilitas agar terpenuhi hak-hak mereka. Hal-hal tersebut merupakan bukti komitmen dari pemerintah pusat dan pemerintah Kota Surakarta untuk menjamin hak seluruh warganya sesuai dengan prinsip-prinsip keadilan.

Undang-Undang tertinggi yaitu UndangUndang Dasar Negara Republik Indonesia Tahun 1945 Pasal 28 I ayat (2) menyebutkan bahwa setiap orang berhak bebas dari perlakuan yang diskriminatif atas dasar apapun dan berhak mendapatkan perlindungan terhadap perlakuan yang bersifat diskriminatif itu. Peraturan di bawahnya terdapat Undang-Undang N0 13 Tahun 2003 Tentang Ketenagakerjaan yang menjamin kesamaan kesempatan serta perlakuan tanpa diskrimansi atas dasar apapun untuk mewujudkan kesejahteraan. Pasal 5 UU No 13 Tahun 2003 mengamanatkan perihal kesempatan bagi disabilitas, bahwa setiap tenaga kerja memiliki kesempatan yang sama tanpa diskriminasi untuk memperoleh pekerjaan. Selanjutnya dalam pasal 19 disebutkan mengenai pelatihan kerja yang dikhususkan bagi disabilitas. Pasal tersebut berisi perintah mengenai penyediaan pelatihan kerja bagi tenaga kerja penyandang cacat dilaksanakan dengan memperhatikan jenis, derajat kecacatan dan kemampuan tenaga kerja penyandang cacat yang bersangkutan. Pasal 67 ayat (1) UU No 13 Tahun 2003 Tentang Ketenagakerjaan juga mengatur hingga masalah perlindungan bagi disabilitas, pengusaha yang mempekerjakan tenaga kerja penyandang cacat wajib memberikan perlindungan sesuai dengan jenis dan derajat kecacatannya. Proses rekrutmen hingga on the job training dan perlindungan tenaga kerja bagi disabilitas yang telah diatur dalam sebuah perUndang-Undangan tersebut menjadi peluang bagi disabilitas dalam mengisi ruang-ruang kosong formasi kebutuhan tenaga kerja baik dalam lingkup pemerintahan, Badan Usaha Milik Negara (BUMN), Badan Usaha Milik Daerah (BUMD) dan swasta.

Undang-Undang memperkuat posisi kaum rentan khususnya disabilitas agar terpenuhi hak mereka, pemerintah Indonesia juga telah mengeluarkan Undang-Undang No 4 Tahun 1997 Tentang Penyandang Cacat. Regulasi tersebut mengatur khusus perihal kaum rentan yang mengalami kecacatan baik cacat fisik, mental serta cacat mental dan fisik. Salah satu pasal mengatur perihal pemenuhan hak disabilitas dalam pekerjaan dan penghidupan yang layak sesuai dengan jenis dan derajat kecacatan, pendidikan, dan kemampuannya yang mana hal ini terdapat dalam pasal 6 poin 2 . Penyediaan pekerjaan berdampak pada pemenuhan hak kaum disabilitas akan aksesibilitas dalam rangka kemandiriannya yang tertuang pada pasal 6 poin 4 . 
Undang-Undang Nomor. 4 Tahun 1997 tentang Penyandang Cacat Pasal 14, mengamanatkan bahwa perusahaan negara dan swasta memberikan kesempatan dan perlakuan yang sama kepada penyandang cacat dengan mempekerjakan penyandang cacat di perusahaannya sesuai dengan jenis dan derajat kecacatan, pendidikan, dan kemampuannya, yang jumlahnya disesuaikan dengan jumlah karyawan dan/atau kualifikasi perusahaan. Penjelasan pasal 14 UU Penyandang Cacat adalah setiap perusahaan harus mempekerjakan sekurang-kurangnya 1 (satu) orang penyandang cacat yang memenuhi persyaratan dan kualifikasi pekerjaan yang bersangkutan, untuk setiap 100 (seratus) orang karyawan. Perusahaan yang menggunakan teknologi tinggi harus mempekerjakan sekurang-kurangnya 1 (satu) orang penyandang cacat yang memenuhi persyaratan dan kualifikasi pekerjaan yang bersangkutan walaupun jumlah karyawannya kurang dari 100 (seratus) orang. Pasal 14 ini kemudian akan diturunkan Pasal 19 Peraturan Daerah Kota Surakarta terkait regulasi yang menagtur kesetaraan disabilitas.

Tahun 2011 pemerintah pusat juga telah turut menetapkan Undang-Undang Republik Indonesia Nomor 19 Tahun 2011 Tentang Pengesahan Convention On The Rights Of Persons With Disabilities (Konvensi Mengenai Hak-Hak Penyandang Disabilitas). Hal ini merupakan tindak lanjut dari Pemerintah
Indonesia telah menandatangani Convention on the Rights of Persons with Disabilities (Konvensi mengenai Hak-Hak Penyandang Disabilitas) pada tanggal 30 Maret 2007 di New York sehingga negara Indonesia memiliki komitmen untuk meratifikasi Konvensi tersebut.

Pada regulasi tingkat daerah di Kota Surakarta terdapat Peraturan Daerah Kota Surakarta No 2 Tahun 2008 Tentang Kesetaraan Disabilitas telah menjadi penguat penyediaan akses bagi disabilitas memasuki dunia kerja. Pasal 4 Perda ini mengamanatkan bahwa dalam kesetaraan disabilitas diarahkan salah satunya pada pemenuhan hak-hak ketenagakerjaan bagi disabilitas. Selain itu didukung dalam pasal 11 disebutkan bahwa pelayanan hakhak disabilitas oleh pemerintah daerah salah satunya meliputi kesempatan kerja. Adanya komitmen dari regulasi-regulasi tersebut menjadi peluang bagi kaum disabilitas masuk dalam dunia kerja. Bagan dari urutan regulasi dari tingkat pusat hingga daerah dapat dilihat dalam bagan 1 dan tabel 1 berikut: 
Tabel 1

Peluang Aksesbilitas Kesempatan Kerja Disabilitas dalam PerUndang-Undangan

\begin{tabular}{|c|c|c|c|}
\hline No & Regulasi & Pasal & Peluang bagi Disabilitas \\
\hline (1) & (2) & (3) & (4) \\
\hline 1 & $\begin{array}{l}\text { Undang-Undang Dasar } \\
\text { Negara Republik Indonesia } \\
\text { Tahun } 1945\end{array}$ & $\begin{array}{l}\text { Pasal } 28 \\
\text { I ayat } \\
(2)\end{array}$ & $\begin{array}{l}\text { setiap orang berhak bebas dari } \\
\text { perlakuan yang diskriminatif atas } \\
\text { dasar apapun dan berhak mendapatkan } \\
\text { perlindungan terhadap perlakuan yang } \\
\text { bersifat diskriminatif itu }\end{array}$ \\
\hline \multirow[t]{3}{*}{2.} & \multirow[t]{3}{*}{$\begin{array}{ll}\text { Undang-Undang } & \text { No } 4 \\
\text { Tahun } 1997 & \text { Tentang } \\
\text { Penyandang Cacat } & \end{array}$} & $\begin{array}{l}\text { Pasal } 6 \\
\text { poin } 2\end{array}$ & $\begin{array}{l}\text { pemenuhan hak disabilitas dalam } \\
\text { pekerjaan dan penghidupan yang layak } \\
\text { sesuai dengan jenis dan derajat } \\
\text { kecacatan, pendidikan, dan } \\
\text { kemampuannya }\end{array}$ \\
\hline & & $\begin{array}{ll}\text { Pasal } 6 \\
\text { poin } 4\end{array}$ & $\begin{array}{l}\text { pemenuhan hak kaum disabilitas akan } \\
\text { aksesibilitas dalam rangka } \\
\text { kemandiriannya }\end{array}$ \\
\hline & & Pasal 14 & $\begin{array}{l}\text { Perusahaan negara dan } \\
\text { memberikan kesempatan dan } \\
\text { perlakuan yang sama kepada } \\
\text { penyandang cacat dengan } \\
\text { mempekerjakan penyandang cacat di } \\
\text { perusahaannya sesuai dengan jenis dan } \\
\text { derajat kecacatan, pendidikan, dan } \\
\text { kemampuannya, yang jumlahnya } \\
\text { disesuaikan dengan jumlah karyawan } \\
\text { dan/atau kualifikasi perusahaan. }\end{array}$ \\
\hline \multirow[t]{3}{*}{3.} & \multirow[t]{3}{*}{$\begin{array}{ll}\text { Undang-Undang } & \text { N0 } 13 \\
\text { Tahun 2003 } & \text { Tentang } \\
\text { Ketenagakerjaan } & \end{array}$} & Pasal 5 & $\begin{array}{lcr}\text { setiap tenaga } & \text { kerja } & \text { memiliki } \\
\text { kesempatan yang } & \text { sama } & \text { tanpa } \\
\text { diskriminasi } & \text { untuk } & \text { memperoleh } \\
\text { pekerjaan } & & \end{array}$ \\
\hline & & pasal 19 & $\begin{array}{l}\text { penyediaan pelatihan kerja bagi tenaga } \\
\text { kerja penyandang cacat dilaksanakan } \\
\text { dengan memperhatikan jenis, derajat } \\
\text { kecacatan dan kemampuan tenaga } \\
\text { kerja penyandang cacat yang } \\
\text { bersangkutan }\end{array}$ \\
\hline & & Pasal 67 & mempekerjakan \\
\hline
\end{tabular}




\begin{tabular}{|c|c|c|c|}
\hline & & ayat (1) & $\begin{array}{l}\text { tenaga kerja penyandang cacat wajib } \\
\text { memberikan perlindungan sesuai } \\
\text { dengan jenis dan derajat kecacatannya }\end{array}$ \\
\hline 4. & $\begin{array}{l}\text { Undang-Undang Republik } \\
\text { Indonesia Nomor } 19 \text { Tahun } \\
2011 \text { Tentang Pengesahan } \\
\text { Convention On The Rights } \\
\text { Of Persons } \quad \text { With } \\
\text { Disabilities (Konvensi } \\
\text { Mengenairak-Hak } \\
\text { Penyandang Disabilitas) }\end{array}$ & & \\
\hline \multirow[t]{5}{*}{5.} & \multirow{5}{*}{ 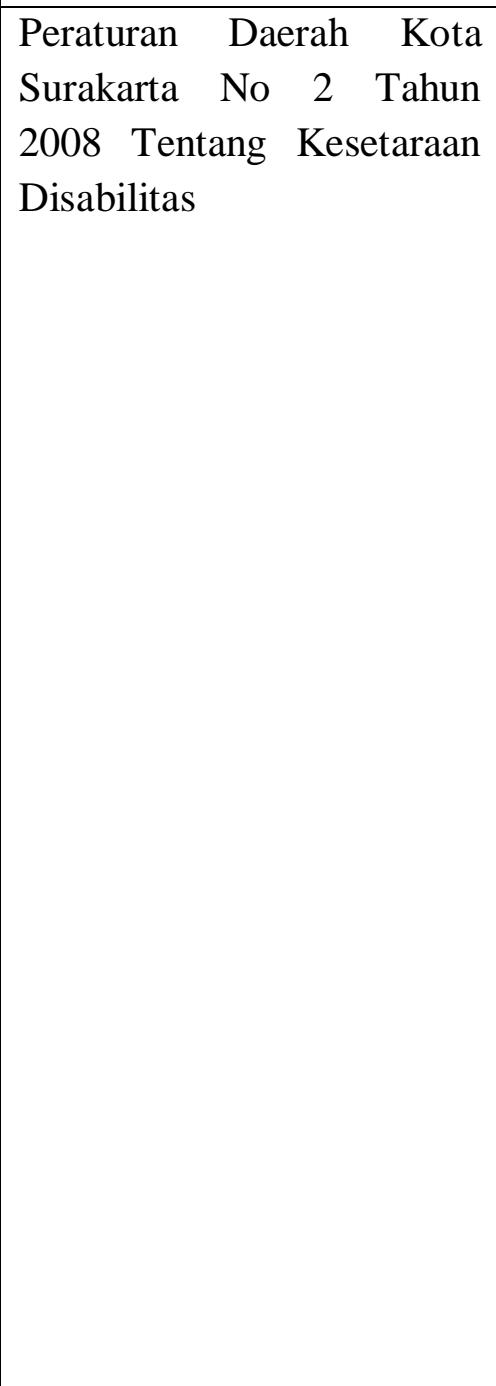 } & Pasal 4 & $\begin{array}{l}\text { kesetaraan disabilitas diarahkan salah } \\
\text { satunya pada pemenuhan hak-hak } \\
\text { ketenagakerjaan bagi disabilitas }\end{array}$ \\
\hline & & Pasal 11 & $\begin{array}{l}\text { pelayanan hak-hak disabilitas oleh } \\
\text { pemerintah daerah salah satunya } \\
\text { meliputi kesempatan kerja }\end{array}$ \\
\hline & & $\begin{array}{l}\text { Pasal } 19 \\
\text { ayat (1) }\end{array}$ & $\begin{array}{l}\text { Disabilitas mempunyai kesempatan } \\
\text { untuk membuka usaha sendiri dan/atau } \\
\text { masuk bursa kerja umum, sesuai } \\
\text { minat, bakat, dan kemampuannya } \\
\text { sebagai bagiar perwujudan aktualisasi } \\
\text { diri }\end{array}$ \\
\hline & & $\begin{array}{l}\text { Pasal } 19 \\
\text { ayat (2) }\end{array}$ & $\begin{array}{l}\text { Badan Usaha Milik Negara, Badan } \\
\text { Usaha Milik Daerah maupun Swasta } \\
\text { yang mempekerjakan sekurang- } \\
\text { kurangnya } 100 \text { (seratus) orang harus } \\
\text { mempekerjakan } 1 \text { (satu) orang } \\
\text { disabilitas sesuai dengan persyaratan, } \\
\text { kualifikas pekerjaan serta jenis } \\
\text { kecacatannya. }\end{array}$ \\
\hline & & $\begin{array}{l}\text { Pasal } 19 \\
\text { ayat (3) }\end{array}$ & $\begin{array}{l}\text { Disabilitas mempunyai kesempatan } \\
\text { yang sama untuk menjadi Pegawai } \\
\text { Negeri Sipil dan berkarir sesuai } \\
\text { dengan ketentuan Peraturan } \\
\text { Perundang-undangan yang berlaku. }\end{array}$ \\
\hline
\end{tabular}

Sumber: Diolah dari berbagai sumber 


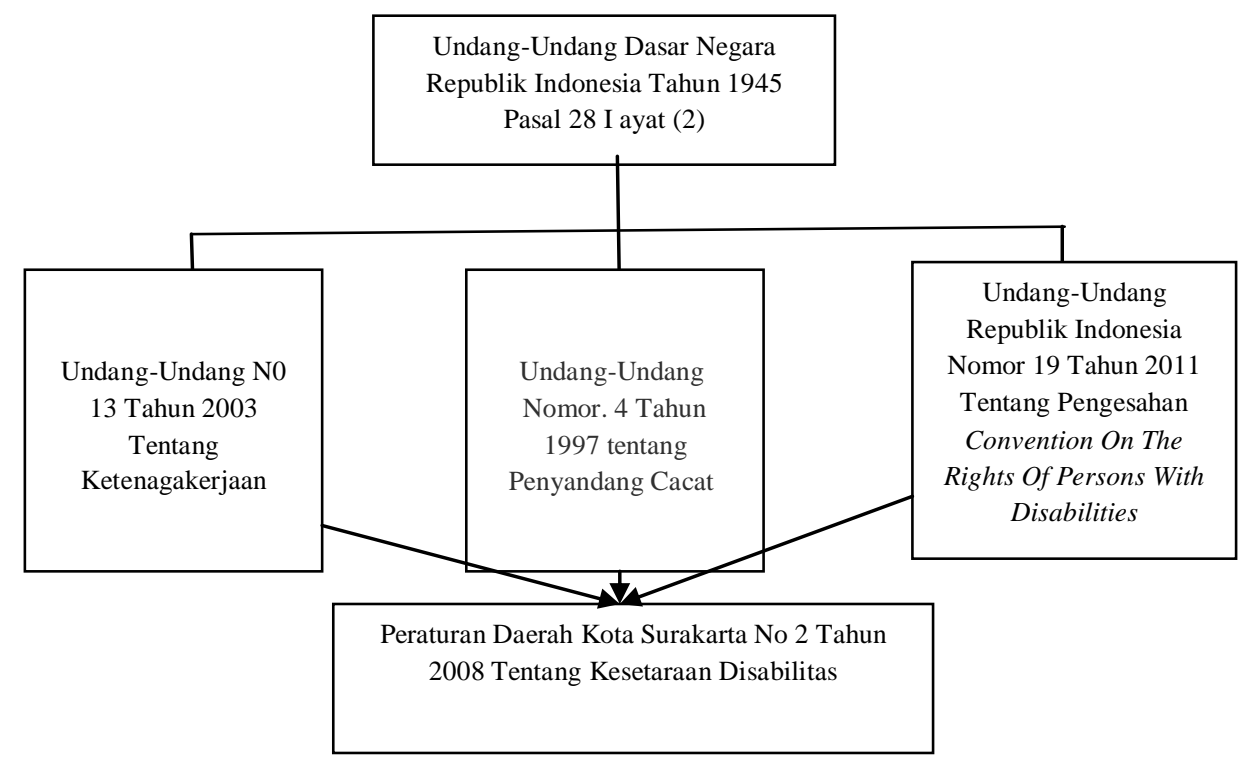

Bagan 1

Regulasi yang Mengatur Peluang Disabilitas dalam Kesempatan Kerja

\section{b. Tantangan Disabilitas dalam Memasuki Dunia Kerja}

Ketika aksesbilitas kesempatan kerja bagi disabilitas telah terbuka luas, hal ini tidak serta merta mampu terimplementasikan dengan optimal di dunia kerja. Terdapat tangtangan-tangtangan yang harus dihadapi disabilitas dalam pemenuhan hak mendapatkan pekerjaan yang layak bagi mereka. Hasil pengamatan penulis bahwa proses rekrutmen yang ada saat ini masih bias terhadap pemenuhak hak disabilitas.

Perusahaan masih berkehendak untuk mencari sumber daya manusia yang berkualitas tanpa kecacatan. Hal ini terlihat dari proses seleksi yang dijalankan baik itu di perusahaan swasta, BUMD, BUMN dan organisasi pemerintahan. Persayaratan yang digunakan dalam proses seleksi masih banyak yang mensyaratakan kesempurnaan jasmani dan mental dari para pelamar. Menurut Noemijati (2008:
561) permasalahan yang sering dihadapai organisasi adalah kenyataan bias ketika proses tes untuk seleksi dilaksanakan. Kusumardani S., Diah (2005: 76) mengidentifikasi bahwa mengelola diversitas tenaga kerja dengan jalan menghormati karyawan merupakan salah satu tantangan yang dihadapi oleh perusahaan saat ini. Tenaga kerja dengan berbeda karakteristik akan muncul pula tantangan terkait cara bertindak dan berkomunikasi yang berbeda (Kusumardani S., Diah, 2005: 84).

Tantangan disabilitas dalam memasuki dunia kerja berikutnya adalah terkait sikap terhadap diservitas yang muncul, masyarakat masih belum dapat berlaku objektif terhadap penerimaan penilaian pada perbedaan (Junaedi, C. marliana, 2003: 25). Hwa, Magdalene Ang Chooi (2005: 183) dalam sebuah penelitian kuantitatifnya menyimpulkan bahwa kaum 
disabilitas juga akan menghadapi kesulitan dalam promosi kerja dan peningkatan upah, " Collectively, the study findings revealed that disability effect was apparent when promotability was the criterion variable. However, disability did not have significant impact on salary progression". Jika melihat faktor tantangan yang muncul dari dalam diri disabilitas tentunya berkaitan dengan kompetensi dan kapasitas disabilitas dalam bekerja. Minimnya lapangan pekerjaan yang memperkerjakan disabilitas dapat dikarenakan pertimbangan kapasitas kerja disabilitas. Minimnya pembentukan sumber daya manusia dengan kebutuhan khusus akan berdampak bagi kaum disabilitas dalam menembus kesempatan kerja yang semakin sempit meskipun regulasi nasional dan daerah telah mengamanatkan kuota kesempatan kerja bagi disabilitas.

\section{Penutup}

Setaip regulasi daerah dan nasional yang telah ditetapkan di Kota Surakarta pada khususnya dan Indonesia pada umumnya telah memberikan ruang-ruang pemenuhan hak disabilitas dalam hal kesempatan kerja. Akan tetapi, tantangan yang muncul dalam praktik pelaksanaan kesempatan kerja bagi disabilitas masih harus mereka hadapi. Ada beberapa faktor yang menjadi tantangan pelaksanaan pengelolaan diversitas ini yaitu pertama, banyaknya praktik diskriminasi. Kedua, proses seleksi kerja yang. Ketiga, stereotip yang diberikan kepada kaum disabilitas.

Artikel ini dapat memberikan beberapa rekomendasi yang penulis ajukan agar dapat berkontribusi lebih baik lagi dalam upaya pemenuhan hak disabilitas dan pengelolaan diversitas dalam dunia kerja. Kajian mengenai jumlah perusahaan dan instansi kerja swasta dan publik yang telah mengimplementasikan pasal 14 UU no 4 tahun 1997 dan Pasal 19 Perda Kota Surakarta No 2 Tahun 2008 dapat dilakukan di Kota Surakarta. Hal ini dapat digunakan oleh pemangku kebijakan memberikan reward bagi perusahaan dan organisasi kerja yang telah menyediakan ruang bekerja bagi disabilitas dan punishment bagi perusahaan dan organisasi kerja yang belum mengimplemntasikan regulasi tersebut. Rekomendasi berikutnya adalah perlu adanya surat keputusan pada masingmasing perusahaan dan organisasi kerja terkait pasal 14 UU no 4 tahun 1997 dan Pasal 19 Perda Kota Surakarta No 2 Tahun 2008 agar memperkuat komitmen perusahaan dan organisasi kerja memberikan kuota kesempatan kerja bagi disabilitas sebesar $1 \%$. Level top manajer dan manajer sumber daya manusua harus mampu melakukan manajemen keanekaragaman secara efisien dan efektif dengan menempatkan pekerja disabilitas sesuai derajat kecacatatannya.

\section{Daftar Pustaka}

Condrey, Stephen E. Handbook of Human resource Management in Government. 2005. United States.

Hwa, Magdalene Ang Chooi. Rational Tactics and Work Outcomes: Differential Effects of Disability. International Journal of Social Science and Humanity, Vol 2, No 3, May 2012. 
Junaedi, C. Marliana. Mengelola Diversitas: Penyebab Kegagalan dan Model yang Efektif. Kinerja Volume 7, No 1, Tahun 2003. Hal 22-28.

Kusumardhani S., Diah. Diversitas Tenaga Kerja: Tantangan dan Strategi Pengelolaannya. Sinergi Vol 7, No 2, 2005. Hal 79-86.

Noermijati. Pentingnya Memanage Keanekaragaman/Diversity dalam Organisasi di Era Global. Jurnal Apilkasi Manajemen Volume 7 Nomor 3 Agustus 2009.

Undang-Undang Dasar Negara Republik Indonesia Tahun 1945.

Undang-Undang Nomor. 4 Tahun 1997 tentang Penyandang Cacat.

Undang-Undang No 13 Tahun 2003 Tentang Ketenagakerjaan.

Undang-Undang Republik Indonesia Nomor 19 Tahun 2011 Tentang Pengesahan Convention On The Rights Of Persons With Disabilities.

Peraturan Daerah Kota Surakarta No 2 Tahun 2008 Tentang Kesetaraan Disabilitas. 
Spirit Publik Volume 12, Nomor 2, Oktober 2017

Halaman 83-93

P-ISSN. 1907-0489 E-ISSN 2580-3875 